\title{
Study on the formation of PCDD/Fs in PVC chemical looping combustion
}

\author{
BI Wen-zhuo ${ }^{1,2}$, ZHAO Rui-dong ${ }^{1, *}$, CHEN Tian-ju ${ }^{1}$, WU Jing-li ${ }^{1}$, WU Jin-hu ${ }^{1}$ \\ ${ }^{1}$ Key Laboratory of Biofuels, Qingdao Institute of Bioenergy and Bioprocess Technology, Chinese Academy of Sciences, Qingdao 266101, \\ China; \\ ${ }^{2}$ University of Chinese Academy of Sciences, Beijing 100049, China
}

\begin{abstract}
CaSO}_{4}$ oxygen carriers with silica sol were prepared and their reaction performances with $\mathrm{CH}_{4}, \mathrm{CO}$ and $\mathrm{H}_{2}$ were experimentally investigated. The formation characteristics of polychlorinated dibenzo-p-dioxins and dibenzofurans (PCDD/Fs) in PVC combustion by means of chemical looping combustion (CLC) based on $\mathrm{CaSO}_{4}$ oxygen carrier and air were studied in a tube furnace system. The results show that $\mathrm{CaSO}_{4}$ oxygen carriers with silica sol can be completely reduced by $\mathrm{CH}_{4}, \mathrm{CO}$ and $\mathrm{H}_{2}$. The reaction time of $\mathrm{CH}_{4}$ and $\mathrm{H}_{2}$ is much shorter than $\mathrm{CO}$. The chemical looping combustion of $\mathrm{PVC}$ can effectively inhibit the formation of $\mathrm{PCDD} / \mathrm{Fs}$. The yield and International Toxicity Equivalent Quantity (I-TEQ) of PCDD/Fs produced in CLC are 2270.9 pg/g and 290.2 $\mathrm{pg}(\mathrm{I}-\mathrm{TEQ}) / \mathrm{g}$, much lower than those in air combustion which are $34172.5 \mathrm{pg} / \mathrm{g}$ and $732.8 \mathrm{pg}(\mathrm{I}-\mathrm{TEQ}) / \mathrm{g}$. It is mainly because fuel doesn't directly contact with $\mathrm{O}_{2}$ in CLC, the oxidative cleavage of large carbon molecule and the conversion from $\mathrm{HCl}$ to $\mathrm{Cl}_{2}$ are significantly reduced which will inhibit the low temperature de novo synthesis and precursors reaction of $\mathrm{PCDD} / \mathrm{Fs}$.
\end{abstract}

Key Words: chemical looping combustion; PCDD/Fs; PVC; oxygen carrier; calcium sulfate

The disposal of combustible solid waste (CSW) is one of the severely environmental problems in the world ${ }^{[1]}$. Composting, landfill and incineration are the common treatment methods of MSW. Incineration is the main developing direction in combustible solid waste management because of its small occupation area, stable and reliable operation and good reduction ${ }^{[2]}$. But incineration of CSW is easy to produce PCDD/Fs and other toxic substances, which is harmful to human health. So its development is controversially ${ }^{[3]}$. Hutzinger et $\mathrm{al}^{[4]}$ found that de novo synthesis and precursor reaction are the main generating ways of $\mathrm{PCDD} / \mathrm{Fs}$ in $\mathrm{CSW}$ incineration. $\mathrm{O}_{2}$ plays an important role in the two reactions ${ }^{[5]}$. Therefore, avoiding the direct contact of $\mathrm{O}_{2}$ and fuel is one of the feasible approaches to inhibit $\mathrm{PCDD} /$ Fs generation in combustion.

Chemical looping combustion (CLC) is a new combustion technology. The oxygen is transferred from air to fuel by means of the circulation of oxygen carriers between air reactor and fuel reactor, which realize the non-contact combustion of fuel and $\mathrm{air}^{[6]}$. The formation of PCDD/Fs may be greatly inhibited by use of CLC to dispose CSW, because there is no direct contact between free oxygen and CSW.
Oxygen carriers are the key element in CLC. The metal oxides such as $\mathrm{Ni}, \mathrm{Cu}$, and $\mathrm{Fe}$ are mainly studied at present ${ }^{[7]}$. However, metal oxides have strong catalysis on the formation of $\mathrm{PCDD} / \mathrm{Fs}^{[8]}$, which may aggravate its generation. By contrast, $\mathrm{CaSO}_{4}$ oxygen carrier is more suitable to dispose high chlorine CSW because of its high oxygen transport capacity, low cost, environmental friendliness and small catalysis on the formation of $\mathrm{PCDD} / \mathrm{Fs}^{\left[{ }^{[9]}\right.}$.

Based on this, $\mathrm{CaSO}_{4}$ oxygen carrier with silica sol is prepared and its reaction characteristics with different fuel gas were experimentally investigated. Finally, the influence of CLC and air combustion on the formation of PCDD/Fs is investigated by use of $\mathrm{CaSO}_{4}$ oxygen carrier with silica sol and PVC.

\section{Experimental}

\subsection{Materials and oxygen carrier preparation}

Reagent: $\mathrm{CaSO}_{4}$ (Sinopharm Chemical Reagent Co., Ltd.); silica sol (Qingdao Hengshengda Chemical Co., Ltd.); PVC (Sinopec Qilu Co., Ltd, Shandong, China).

Received: 15-Feb-2015; Revised: 06-May-2015.

Foundation item: Supported by the National Basic Research Program of China (973 program, 2011CB201502); China Postdoctoral Science Foundation Funded Project (2014M551978).

*Corresponding author: ZHAO Rui-dong, Tel: 86-0532-80662764, E-mail: zrd_gscas@126.com, WU Jin-hu, Tel: 86-0532-80662761, E-mail: wujh@qibebt.ac.cn.

Copyright $($ ) 2015, Institute of Coal Chemistry, Chinese Academy of Sciences. Published by Elsevier Limited. All rights reserved. 
Preparation method: $\mathrm{CaSO}_{4}$ oxygen carrier was prepared by mechanical mixing method. First, silica sol and $\mathrm{CaSO}_{4}$ were mixed together according to the same concentration. Then the mixture was dried at room temperature for $24 \mathrm{~h}$ and finally calcined at $900^{\circ} \mathrm{C}$ for $5 \mathrm{~h}$. The content of $\mathrm{CaSO}_{4}$ in the fresh oxygen carrier is $87 \%$.

\subsection{Characterization of oxygen carrier}

Thermogravimetric analysis was carried out to study the reduction reactivity of oxygen carrier in a magnetic levitation thermogracimetric analyzer (RubothermDyntherm-HP, Holland). First, $50 \mathrm{mg}$ oxygen carrier was loaded in a crucible. Then the temperature was raised and maintained at $900^{\circ} \mathrm{C}$ in Ar atmosphere. Finally, $50 \mathrm{~mL} / \mathrm{min}$ reducing gas $\left(\mathrm{CH}_{4}, \mathrm{H}_{2}\right.$ and $\mathrm{CO}$, respectively) was introduced into the TGA to reduce the oxygen carrier.

The XRD analysis of oxygen carrier was carried out using Bruker D8 ADVANCE XRD system (Bruker) with $\mathrm{Cu} \mathrm{K \alpha}$ radiation $(40 \mathrm{kV} / 40 \mathrm{~mA})$. The scan range was from $5^{\circ}$ to $75^{\circ}$ with $2\left(^{\circ}\right) / \mathrm{min}$ and the step stride is $0.02^{\circ}$.

\subsection{Combustion and PCDD/Fs detection system}

Both the combustion experiments of PVC and measurement of $\mathrm{PCDD} / \mathrm{Fs}$ were carried out in the dioxin laboratory, Zhejiang University. Experiments were carried out in a tubular furnace (Figure 1) comprising three sections and featuring three independent heaters and temperature controllers $\left(t_{\mathrm{a}}, t_{\mathrm{b}}, t_{\mathrm{c}}\right)$. Quartz reaction tube consists of inner tube (i.d. $=20 \mathrm{~mm}$, length $=400 \mathrm{~mm}$ ) and outer tube (i.d. $=25 \mathrm{~mm}$, length $=1000$ $\mathrm{mm})$. Two groups of experiments were conducted and repeated once. The experimental conditions are shown in Table 1. In the experiment, $\mathrm{Ta}$ and $\mathrm{Tb}$ were set at $900^{\circ} \mathrm{C}$ and Tc was room temperature. When the temperature reached set value, oxygen carrier was firstly loaded in the place 5 of inner tube and fixed by the quartz cotton. Then corresponding gas was introduced for $30 \mathrm{~min}$ to purge residual gas. Finally, the quartz boat with PVC was quickly pushed into place 3 of inner tube. The reaction time is $20 \mathrm{~min}$.

The PCDD/Fs in exhaust gas was absorbed with XAD-2 resin and methylbenzene (ice-water bath) at the end of furnace. Then the exhaust gas was analyzed by Online Infrared Flue Gas Analyzer (FT-IR, Gas-met DX4000). The collected dioxins samples were sealed and analyzed by the dioxin laboratory, Zhejiang University.

The calculation formulas of relative generation of $\mathrm{PCDD} / \mathrm{Fs}$ and I-TEQ are:

$C_{i}=A_{i} / B(\mathrm{pg} / \mathrm{g})$

$Q_{i}=C_{i} \times F_{i}(\mathrm{pg}(\mathrm{I}-\mathrm{TEQ}) / \mathrm{g})$

Where $A_{i}, Q_{i}, C_{i}, F_{i}$ represent the detection quality, relative generation, I-TEQ and international toxicity equivalent factor of $i$ kind of PCDD/Fs respectively. $B$ is the PVC quality of the corresponding experiment.

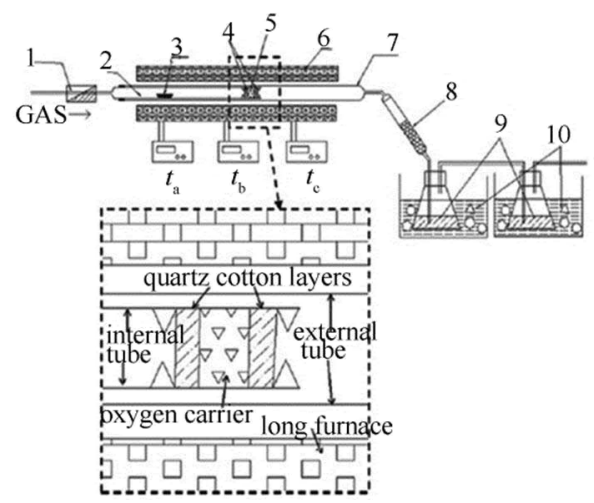

Fig.1 Diagram of PCDD/Fs experimental system

1: mass flow meter; 2 : internal quartz tube; 3 : quartz boat;

4: quartz cotton layers; 5 : oxgen carrier; 6 : long furnace;

7: external quartz tube; 8: XAD resin; 9: toluene; 10: ice bath

Table 1 Experimental conditions of dioxin

\begin{tabular}{|c|c|c|}
\hline Experiment parameter & CLC & Air combustion \\
\hline $\mathrm{PVC} m / \mathrm{g}$ & 1 & 1 \\
\hline $\mathrm{CaSO}_{4} \mathrm{~m} / \mathrm{g}$ & 5 & 0 \\
\hline Atmosphere & $\mathrm{N}_{2}$ & Air \\
\hline Gas flow rate $q /\left(\mathrm{mL} \cdot \mathrm{min}^{-1}\right)$ & 200 & 200 \\
\hline Temperature $t /^{\circ} \mathrm{C}$ & 900 & 900 \\
\hline
\end{tabular}

\section{Results and discussion}

\subsection{Reaction characteristics of oxygen carrier}

Figure 2 shows the reduction reaction TGA curves of $\mathrm{CaSO}_{4}$ oxygen carriers with silica sol in $\mathrm{CH}_{4}, \mathrm{CO}$ and $\mathrm{H}_{2}$ atmosphere. Because the content of $\mathrm{CaSO}_{4}$ in the fresh oxygen carrier is $87 \%$, the actual oxygen transport capacity of the fresh oxygen carrier is $41 \%$. As shown in Figure 2, all of the weight loss of $\mathrm{CaSO}_{4}$ oxygen carriers with silica sol are $40 \%$ in three kinds of atmosphere which is very close to the theoretical value. This is because the oxygen carrier is almost completely reduced and $\mathrm{CaSO}_{4}$ is converted into $\mathrm{CaS}$. Few side reaction is occurred. The reaction is given by Eq. (3) - Eq. (5).

$$
\begin{aligned}
& \mathrm{CaSO}_{4}+\mathrm{CH}_{4} \rightarrow \mathrm{CaS}+\mathrm{CO}_{2}+2 \mathrm{H}_{2} \mathrm{O} \\
& \mathrm{CaSO}_{4}+4 \mathrm{CO} \rightarrow \mathrm{CaS}+4 \mathrm{CO}_{2} \\
& \mathrm{CaSO}_{4}+4 \mathrm{H}_{2} \rightarrow \mathrm{CaS}+4 \mathrm{H}_{2} \mathrm{O}
\end{aligned}
$$

From Figure 2, it can be seen that the reaction time of $\mathrm{CH}_{4}$ and $\mathrm{H}_{2}$ is shorter, which are 15 and $20 \mathrm{~min}$ respectively. However, the reaction time of CO is more than $100 \mathrm{~min}$. It is demonstrated that the reaction performance of oxygen carrier with $\mathrm{CH}_{4}$ and $\mathrm{H}_{2}$ is better than $\mathrm{CO}$. 


\subsection{XRD characterization of oxygen carrier}

Figure 3 shows the XRD analysis of oxygen carrier before and after reaction in three kinds of atmosphere. As shown in Figure 3(a), the main component of the fresh oxygen carrier is $\mathrm{CaSO}_{4}$. The inert component $\mathrm{SiO}_{2}$ is amorphous. From Figure 3(b), the main components of reduced oxygen carrier are $\mathrm{CaS}$ and $\mathrm{CaSiO}_{3}$. According to the weight loss rate in section 2.1, $\mathrm{CaS}$ is in the majority and $\mathrm{CaSiO}_{3}$ is formed by the co-product $\mathrm{CaO}$ and $\mathrm{SiO}_{2}$.

\subsection{SEM characterization of oxygen carrier}

Figure 4 shows the SEM analysis of oxygen carrier before and after reaction. As shown in Figure 4, the particle size of fresh $\mathrm{CaSO}_{4}$ oxygen carrier is large and then decreases after reaction. The surfaces of oxygen carrier reduced by $\mathrm{CH}_{4}$ and
$\mathrm{H}_{2}$ are rough and porous. So the oxygen carrier can fully react with fuel gas which will reduce the reaction time. By contrast, the surface of oxygen carrier reduced by $\mathrm{CO}$ is smooth and has fewer pores. Thus, fuel gas is difficult to get inside of the oxygen carrier which increases the reaction time.

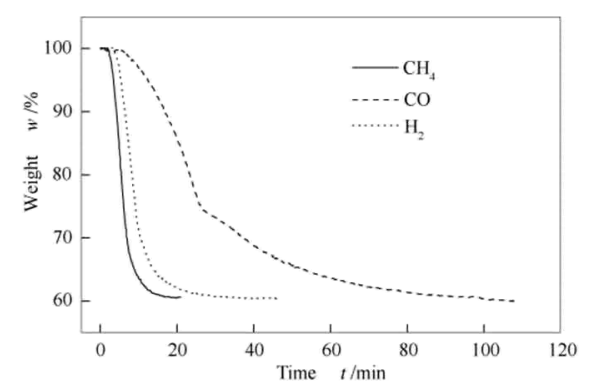

Fig.2 TGA curve of oxygen carrier under reductive atmosphere

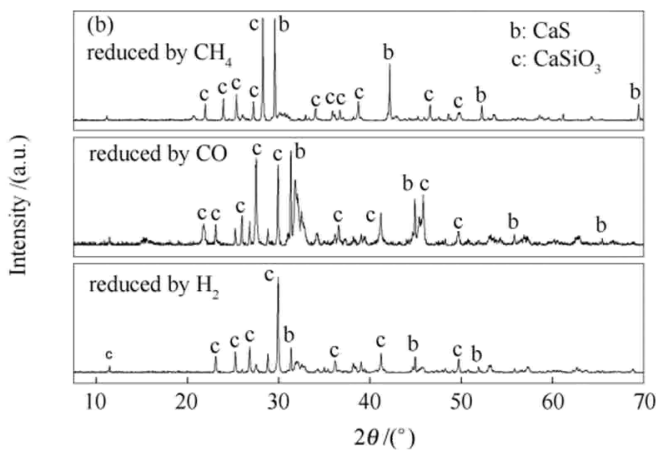

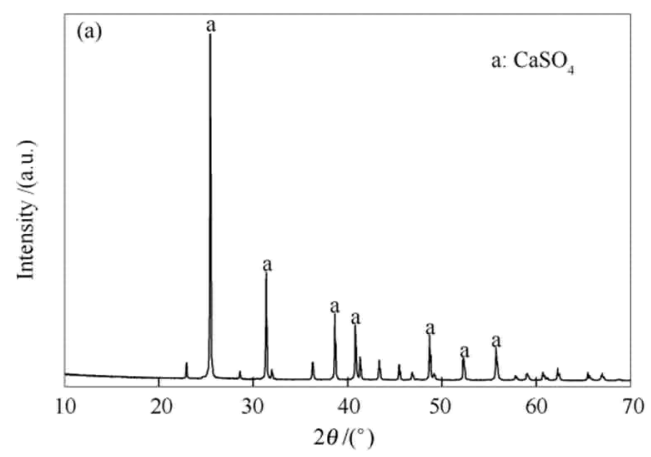

Fig.3 XRD results of $\mathrm{CaSO}_{4}$ oxygen carrier with Silica Sol

(a): fresh; (b): reduced
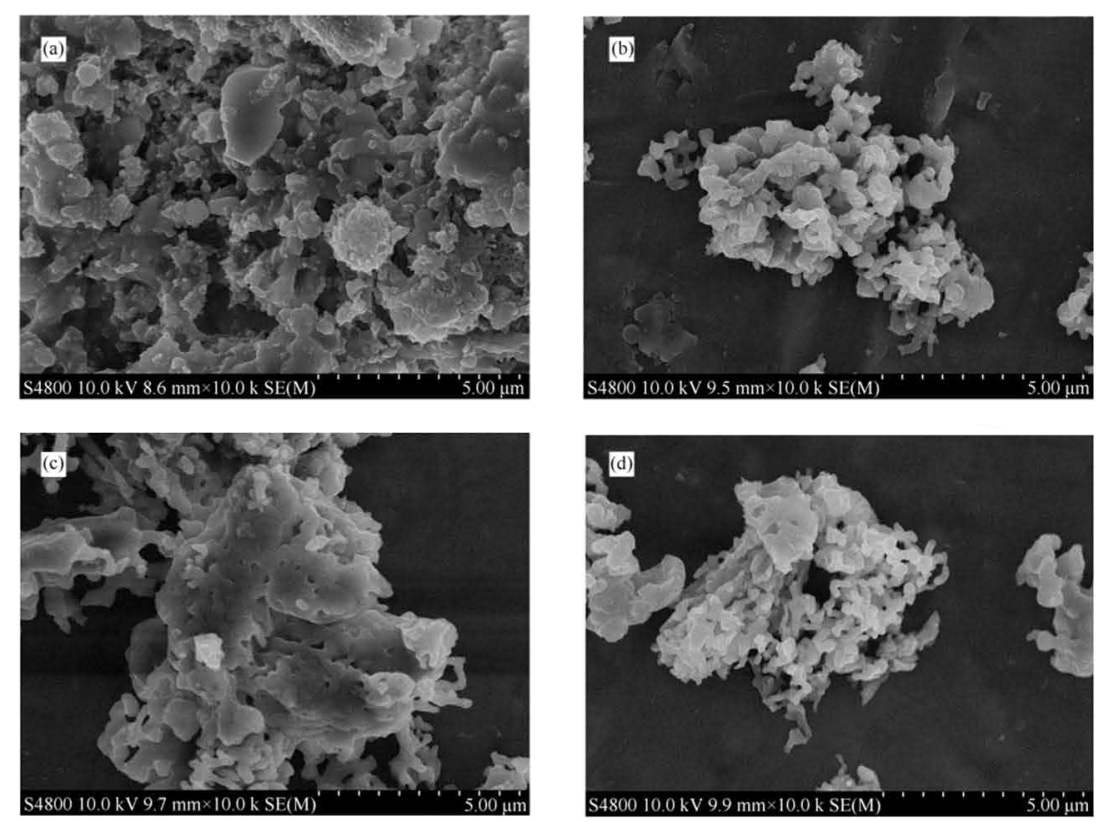

Fig.4 SEM images of $\mathrm{CaSO}_{4}$ oxygen carrier with silica sol (a): fresh; (b): reduced by $\mathrm{CH}_{4}$; (c): reduced by $\mathrm{CO}$; (d): reduced by $\mathrm{H}_{2}$ 


\subsection{Formation characteristics of PCDD/Fs in PVC combustion}

In order to study the completeness of PVC chemical looping combustion, the exhaust gas is firstly analyzed. Figure 5 shows the volume fraction profiles of exhaust gas in chemical looping combustion. As shown in Figure 5, the volume fraction of $\mathrm{CO}_{2}$ increased gradually which means that Eq. (3) - Eq. (5) began to take place. The volume fraction of $\mathrm{CO}_{2}$ reached the maximum of $8 \%$ at $14 \mathrm{~min}$. Then it rapidly decreases and approached 0 at 17 min which means the end of reaction. During the whole reaction, the concentration of $\mathrm{CO}$ and $\mathrm{CH}_{4}$ was less than $10^{-6}$. It indicates that the chemical looping combustion of $\mathrm{PVC}$ is complete.

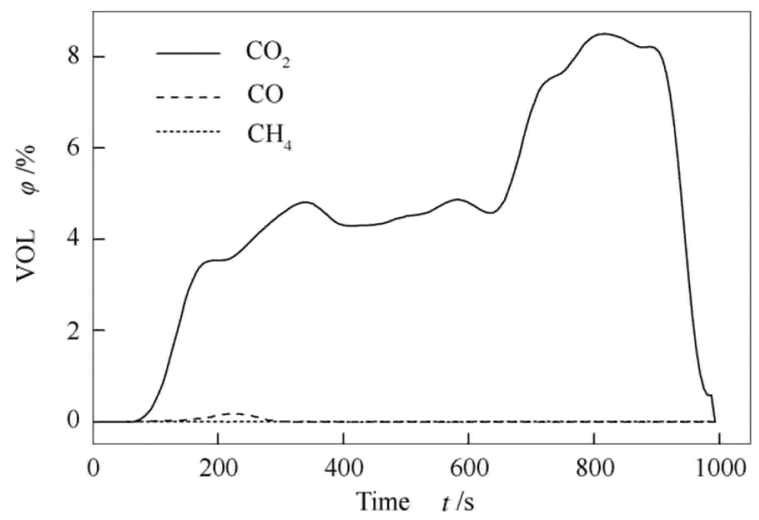

Fig.5 Exhaust gas volume fraction profiles in chemical looping combustion

Figure 6 and Figure 7 respectively show the generation and I-TEQ of toxic PCDD/Fs profiles in different PVC combustion methods. The data had taken the average of double repeated experimental results because the error is acceptable. As shown in Figure 6, in the air combustion of PVC, O8CDFs and H7CDFs were the major homologs of PCDD/Fs, and their proportion accounted for $86.2 \%$. The total production of PCDFs was much higher than PCDDs and the ratio of PCDDs to PCDFs was 0.11. However, O8CDDs, H6CDFs and O8CDFs were the major homologs by use of CLC method and their proportion was $56.7 \%$. The total production of PCDFs was close to PCDDs and the ratio of PCDDs to PCDFs was 0.83. From Figure 7, P5CDFs and
H6CDFs were the main source of I-TEQ in the air combustion, and their proportion was $73.9 \%$. But in the CLC, P5CDDs was the biggest contributor to I-TEQ whose proportion accounted for $47.1 \%$.

Table 2 shows the results of total PCDD/Fs and I-TEQ in different combustion methods. As shown in Table 2, the concentration of total $\mathrm{PCDD} / \mathrm{Fs}$ and I-TEQ in chemical looping combustion were $2270.9 \mathrm{pg} / \mathrm{g}$ and $290.2 \mathrm{pg}(\mathrm{I}-\mathrm{TEQ}) / \mathrm{g}$ respectively, much lower than those in air combustion which were $34172.5 \mathrm{pg} / \mathrm{g}$ and $732.8 \mathrm{pg}(\mathrm{I}-\mathrm{TEQ}) / \mathrm{g}$. It means the CLC method can effectively inhibit the formation of PCDD/Fs in PVC combustion.

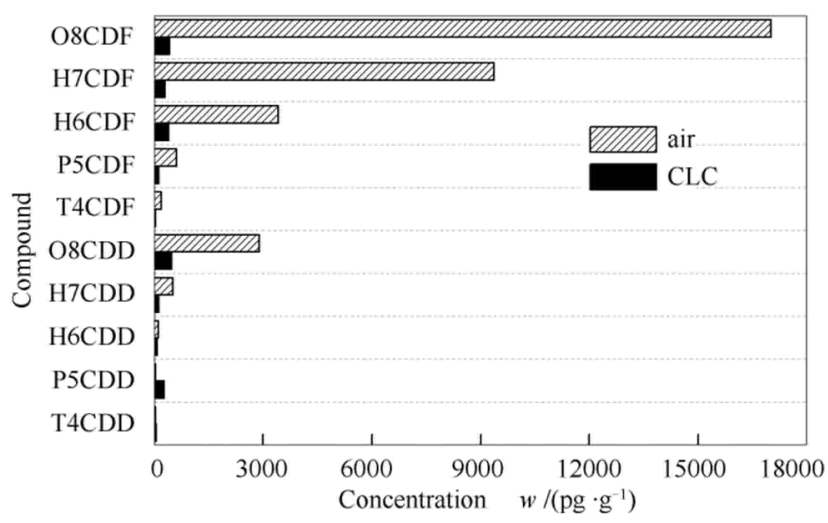

Fig.6 Toxic PCDD/Fs homologue profiles for PVC combustion

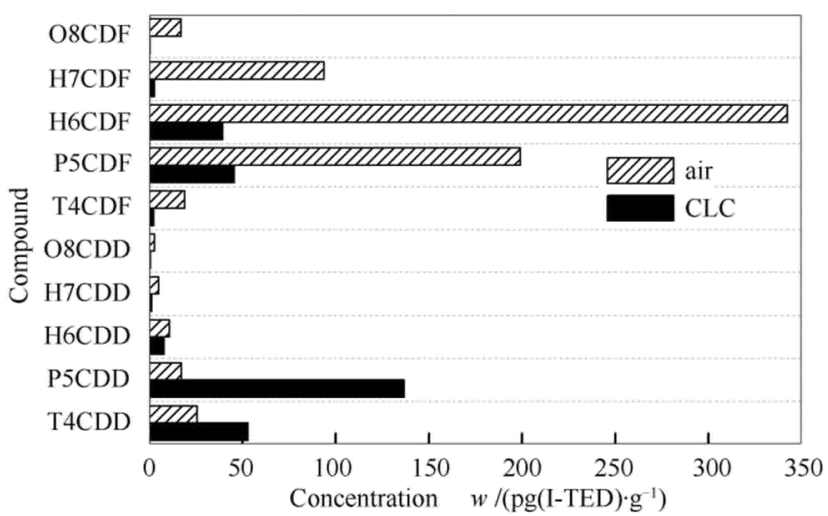

Fig.7 I-TEQ of toxic PCDD/Fs homologue profiles for PVC combustion

Table 2 Results of PCDD/Fs and I-TEQ

\begin{tabular}{cccc}
\hline \multirow{2}{*}{ Method } & & Content $w /\left(\mathrm{pg} \cdot \mathrm{g}^{-1}\right)$ & \\
\cline { 2 - 4 } & PCDDs & PCDFs & PCDD $/$ Fs \\
\hline CLC & 1007.91 & 1263.022 & 2270.9 \\
Air combustion & 3570.886 & 30601.611 & 34172.5 \\
\hline
\end{tabular}




\subsection{Inhibition mechanism of PCDD/Fs in PVC chemical looping combustion}

In waste incineration, $\mathrm{PCDD} / \mathrm{Fs}$ generated by the mechanism of high-temperature pyrosynthesis is much less than that by low-temperature de novo synthesis and precursor synthesis, and can be ignored ${ }^{[10]}$. According to the study of Buekens et $\mathrm{al}^{[11]}$ and Dickson et al ${ }^{[12]}$, most of the PCDDs are formed by precursor synthesis, and on the contrary PCDFs are mainly generated by de novo synthesis. Therefore, the dominant mechanism of PCDD/Fs formation could be determined by the ratio of PCDDs to PCDFs. When it is larger than 1, precursor synthesis is the predominant mechanism. And when it is smaller than 1, de novo synthesis is dominant. According to the analysis of section 2.4, both the ratios of PCDDs to PCDFs were smaller than 1 under two combustion methods. It means that PCDD/Fs were mainly generated by de novo synthesis in the experiment. The concentration of PCDFs was sharply decreased from $30601.611 \mathrm{pg} / \mathrm{g}$ (in air combustion) to $1263.022 \mathrm{pg} / \mathrm{g}$ (in CLC). And the total I-TEQ was also reduced from $67.1 \mathrm{pg}(\mathrm{I}-\mathrm{TEQ}) / \mathrm{g}$ (in air combustion) to $9.1 \mathrm{pg}(\mathrm{I}-\mathrm{TEQ}) / \mathrm{g}$ (in CLC). By contrast, the decrease of PCDDs in CLC was not obvious. It was about $1 / 3$ of that in air combustion. And the I-TEQ of PCDDs formed in CLC was even higher than that in air combustion. Hence we infer that the chemical looping combustion method can effectively inhibit the de novo synthesis and it also has certain inhibitory effect on the precursor reaction. Thus the formation of PCDD/Fs could be significantly reduced in chemical looping combustion.

There are two possible reasons for above results. On one hand, the influence of $\mathrm{O}_{2}$ on de novo synthesis is larger than precursor reaction. In the de novo synthesis, macromolecular carbon is cracked by the oxidation of $\mathrm{O}_{2}$, and then the aromatic structure separates from macromolecular carbon and forms $\mathrm{PCDD} / \mathrm{Fs}$ through condensation, cyclization and chlorination $^{[13]}$. But in CLC, fuel doesn't directly contact with $\mathrm{O}_{2}$, so the large carbon molecule fracture is difficult to breakdown which will sharply reduce the PCDD/Fs formation by de novo synthesis.

On the other hand, chlorine source is necessary for both de novo synthesis and precursor reaction. $\mathrm{Cl}_{2}$ is the most important chlorine source in the reaction ${ }^{[14]}$. It mainly produced by $\mathrm{HCl}$ and $\mathrm{O}_{2}$ via Deacon Reaction ${ }^{[15]}$.

$$
2 \mathrm{HCl}+\frac{1}{2} \mathrm{O}_{2} \rightarrow \mathrm{Cl}_{2}+\mathrm{H}_{2} \mathrm{O}
$$

From Eq. (6), $\mathrm{O}_{2}$ is the key of transformation from $\mathrm{HCl}$ to $\mathrm{Cl}_{2}$. In the $\mathrm{PVC}$ chemical looping combustion, $\mathrm{HCl}$ produced from $\mathrm{PVC}$ can only contact with $\mathrm{CaSO}_{4}$ instead of free $\mathrm{O}_{2}$. Therefore, the production of $\mathrm{Cl}_{2}$ is sharply reduced, so the chlorinated reaction is greatly weakened and the formation of $\mathrm{PCDD} / \mathrm{Fs}$ is finally inhibited.
However, PCDD/Fs formation mechanism is much more complicated in actual combustion and the dominant reaction mechanism is still controversial. More experiments are needed to study the PCDD/Fs inhibition mechanism in chemical looping combustion.

\section{Conclusions}

$\mathrm{CaSO}_{4}$ oxygen carriers with silica sol can be completely reduced by $\mathrm{CH}_{4}, \mathrm{CO}$ and $\mathrm{H}_{2}$, and the main product is CaS. Few side reactions are happened and $\mathrm{CaSiO}_{3}$ is generated with $\mathrm{SiO}_{2}$. The reaction time of $\mathrm{CaSO}_{4}$ oxygen carriers with $\mathrm{CH}_{4}$ and $\mathrm{H}_{2}$ is shorter than that with $\mathrm{CO}$.

The chemical looping combustion of PVC based on $\mathrm{CaSO}_{4}$ oxygen carrier can effectively inhibit the formation of PCDD/Fs. The concentration of total PCDD/Fs and I-TEQ produced in CLC are $2270.9 \mathrm{pg} / \mathrm{g}$ and $290.2 \mathrm{pg}(\mathrm{I}-\mathrm{TEQ}) / \mathrm{g}$ respectively, much lower than those in air combustion which are $34172.5 \mathrm{pg} / \mathrm{g}$ and $732.8 \mathrm{pg}(\mathrm{I}-\mathrm{TEQ}) / \mathrm{g}$. It is mainly because in CLC fuel doesn't directly contact with $\mathrm{O}_{2}$, the oxidative cleavage of large carbon molecule and the conversion from $\mathrm{HCl}$ to $\mathrm{Cl}_{2}$ are significantly reduced which will inhibit the low temperature de novo synthesis and precursors reaction of $\mathrm{PCDD} / \mathrm{Fs}$.

\section{References}

[1] Cheng H F, Hu Y A. Municipal solid waste (MSW) as a renewable source of energy: Current and future practices in China. Bioresource Technol, 2010, 101(11): 3816-3824.

[2] Jin Y Q. Study on MSW combustion characteristics and a new CFB incineration technology. Hangzhou: Zhejiang University, 2002.

[3] Guideline on pollution prevention and control technologies for solid waste recycling, Ministry of Environmental Protection, 2013.

[4] Hutzinger O, Blumich M J, Berg M, Olie K. Sources and fate of PCDDs and PCDFs: an overview. Chemosphere, 1985, 14(6): 581-600.

[5] Addink R, Olie K. Role of oxygen in formation of polychlorinated dibenzo-p-dioxins/dibenzofurans from carbon on fly ash. Environ Sci Technol, 1995, 29(6): 1586-1590.

[6] Yu Z L, Li C Y, Jing X L, Ding L, Fang Y T, Huang J J. Catalytic chemical looping combustion of coal with iron-based oxygen carrier promoted by $\mathrm{K}_{2} \mathrm{CO}_{3}$. J Fuel Chem Technol, 2013, 41(7): 826-831.

[7] Wang J, Wang W J, Zhu S G, Xiong R H, Liu X Z. Development of oxygen carriers in chemical-looping combustion technology. Mod Chem Ind, 2013, 32(11): 13-17.

[8] Kuzuhara S, Sato H, Kasai E, Nakamura T. Influence of metallic chlorides on the formation of PCDD/Fs during low-temperature 
oxidation of carbon. Environ Sci Technol, 2003, 37(11): $2431-2435$

[9] Guo Q J, Zhang J S, Tian H J. Recent advances in $\mathrm{CaSO}_{4}$ oxygen carrier for chemical-looping combustion process. Chem Eng Commun, 2012, 199(11):1463-1491.

[10] Hinton W S, Lane A M. Synthesis of polychlorinated dioxins over MSW incinerator fly ash to identify catalytic species. Chemosphere, 1991, 23(7): 831-840.

[11] Buekens A, Huang H. Comparative evaluation of techniques for controlling the formation and emission of chlorinated dioxins/furans in municipal waste incineration. J Hazard Mater, 1998, 62(1): 1-33.

[12] Dickson L, Lenoir D, Hutzinger O. Quantitative comparison of de novo and precursor formation of polychlorinated dibenzo-p-dioxins under simulated municipal solid waste incinerator postcombustion conditions. Environ Sci Technol, 1992, 26(9): 1822-1828.

[13] Michael S M, Elmar R A. Chlorophenol reactions on fly ash. 1. Adsorption/desorption equilibria and conversion to polychlorinated dibenzo-p-dioxins. Environ Sci Technol, 1996, 30(1): 225-229.

[14] Gullett B K, Bruce K R, Beach L O, Formation of chlorinated organics during solid waste combustion. Waste Manage Res, 1990, 8: 203-214.

[15] Stanmore B. The formation of dioxins in combustion systems. Combust Flame, 2004, 136(3): 398-427. 